\title{
Efeitos combinados do fósforo e análogo de brassinoesteroides na fase inicial da cana-de-açúcar: crescimento e fotossíntese
}

\begin{abstract}
Diante da iminente escassez de fósforo $(\mathrm{P})$, surge a necessidade de pesquisas para compreensão de estratégias que venham contribuir ao fornecimento desse nutriente para agricultura. Publicações mostram que a atividade hormonal influência beneficamente sobre processos em que o P é vital para ocorrência, destacando os análogos de brassinoesteroides (BR) pela influência no crescimento meristemáticos, sugerindo sinergismo. São escassos os estudos com BR em grandes culturas e sua interação com o $P$, como a cana-de-açúcar. Assim, o objetivo do presente estudo foi avaliar e efeito da aplicação de doses do análogo de BR 24-epibrassinolide $(0 ; 0,5 ; 1,0 ; 2,0 \mathrm{mg}$.L-1), associado à presença ou ausência de fertilização fosfatada sobre os parâmetros de crescimento, fosfatase, micorrização e fotossíntese de plantas jovens de cana-de-açúcar. 0 experimento foi conduzido em casa de vegetação, em DBC com fatorial $4 \times 2$ com seis repetições. A aplicação dos BR proporcionou um incremento nos valores de massa seca radicular até o ponto máximo da curva de 1,27 mg.L-1. A interação P com BR beneficiou seis repetições. A aplicação dos BR proporcionou um incremento nos valores de massa seca radicular até o ponto máximo da curva de $1,27 \mathrm{mg}$.L-1. A interação P com BR beneficiou
respectivamente em $30 \%$ e $48 \%$ os valores de massa seca aérea nas doses 0,5 e $1,0 \mathrm{mg} . L-1$ do hormônio; e apresentou uma correlação de Pearson positiva das doses de BR com adição de $P$ sobre essa variável. A presença de P estimulou todas as variáveis de crescimento da cana-de-açúcar. Os BR desencadearam um pico significativo na atividade da enzima fosfatase ácida na dose de 1,0 mg. L-1 e não afetaram a colonização micorrízica radicular. A temperatura interna da folha e condutância estomática responderam positivamente à adição de P. A assimilação liquida de $\mathrm{CO} 2$ aumentou na presença de P e dobrou em sua interação com BR. Foi constatado uma influência positiva do fósforo, dos brassinoesteroides, assim como sua interação sobre o desenvolvimento inicial da cana-de-açúcar. Os resultados agregam aos estudos a respeito dos BR e são pioneiros sobre a interação com P.
\end{abstract}

Palavras-chave: Crescimento; Fosfatase; Fotossíntese; Micorrizas; 24-epibrassinolide.

\section{Combined effects of phosphorus and analog of brassinoesteroids in the initial phase of sugarcane: growth and photosynthesis}

\begin{abstract}
In view of the imminent shortage of phosphorus $(\mathrm{P})$, there is a need for research to understand strategies that will contribute to the supply of this nutrient for agriculture. Publications show that hormonal activity beneficially influences processes in which $P$ is vital for occurrence, highlighting the analogs of brassinoesteroides (BR) for their influence on meristemmatic growth, suggesting synergism. Studies with BR in large cultures and its interaction with P, such as sugarcane, are scarce. Thus, the aim of the present study was to evaluate and the effect of applying doses of the BR 24-epibrassinolide analogue (0;0.5; $1.0 ; 2.0 \mathrm{mg}$.L-1), associated with the presence or absence of fertilization phosphated on the growth, phosphatase, mycorrhization and doses of the BR 24-epibrassinolide analogue $(0 ; 0.5 ; 1.0 ; 2.0 \mathrm{mg} . \mathrm{L}-1)$, associated with the presence or absence of fertilization phosphated on the growth, phosphatase, mycorrhization and
photosynthesis parameters of young sugarcane plants. The experiment was carried out in a greenhouse, in DBC with factorial $4 \times 2$ with six replications. The application of BR provided an increase in root dry mass values up to the maximum point of the curve of $1.27 \mathrm{mg}$.L-1. The P interaction with BR benefited air dry mass values in doses of 0.5 and $1.0 \mathrm{mg} . \mathrm{L}-1$ of the hormone in $30 \%$ and $48 \%$, respectively; and showed a positive Pearson correlation of BR doses with the addition of P on this variable. The presence of P stimulated all sugar cane growth variables. BR triggered a significant peak in acid phosphatase enzyme activity at a dose of $1.0 \mathrm{mg}$. L-1 and did not affect root mycorrhizal colonization. The internal leaf temperature and stomatal conductance responded positively to the addition of $\mathrm{P}$. Liquid $\mathrm{CO} 2$ assimilation increased in the presence of $\mathrm{P}$ and doubled in its interaction with $\mathrm{BR}$. A positive influence of phosphorus and brassinoesteroids was observed, as well as their interaction on the initial development of sugarcane. The results add to the studies about BR and are pioneering about the interaction with $\mathrm{P}$.
\end{abstract}

Keywords: Growth; Phosphatase; Photosynthesis; Mycorrhizae; 24-epibrassinolide.

Topic: Desenvolvimento, Sustentabilidade e Meio Ambiente

Reviewed anonymously in the process of blind peer.
Received: 04/02/2021 Approved: 25/02/2021
Lucas Ferreira (D)

Universidade Estadual Paulista de Júlio Mesquita Filho, Brasil http://lattes.cnpq.br/1264913582919758

http://orcid.org/0000-0003-4699-3549

eng.agro.lucas@hotmail.com

Luciola Santos Lannes (id

Universidade Estadual Paulista Júlio de Mesquita Filho, Brasil http://lattes.cnpq.br/4457583288339052

http://orcid.org/0000-0002-0603-4071

luciola.lannes@unesp.br

Paulo Alexandre Monteiro de Figueiredo (iD

Universidade Estadual Paulista Júlio de Mesquita Filho, Brasil http://lattes.cnpq.br/4742055389737525

http://orcid.org/0000-0003-4505-6975

paulofigueiredo@dracena.unesp.br

\author{
Glaucia Amorim Faria (iD) \\ Universidade Estadual Paulista Júlio de Mesquita Filho, Brasil \\ http://lattes.cnpq.br/0299844160186806 \\ http://orcid.org/0000-0003-2474-4840 \\ glaucia.a.faria@unesp.br \\ Marcelo Menossi Teixeira (iD) \\ Universidade Estadual de Campinas, Brasil \\ http://lattes.cnpq.br/9861339870761985 \\ http://orcid.org/0000-0002-9211-3787 \\ menossi@lgf.ib.unicamp.br \\ Rafaela Neris Gaspareto (iD \\ Universidade Estadual Paulista Júlio de Mesquita Filho, Brasil \\ http://lattes.cnpq.br/6281330659945694 \\ http://orcid.org/0000-0001-6125-1661 \\ rafagaspareto@hotmail.com
}

Referencing this:

FERREIRA, L.; LANNES, L. S.; FIGUEIREDO, P. A. M.; FARIA, G. A.; TEIXEIRA, M. M.; GASPARETO, R. N.. Efeitos combinados do fósforo e análogo de brassinoesteroides na fase inicial da cana-de-açúcar: crescimento e fotossíntese. Revista Ibero Americana de Ciências Ambientais, v.12, n.2, p.517-529, 2021. DOI:

http://doi.org/10.6008/CBPC2179-6858.2021.002.0044 


\section{INTRODUÇÃO}

A cana-de-açúcar é uma das culturas intensamente exploradas pelo agronegócio brasileiro (CORDEIRO et al., 2019; FERREIRA et al., 2020), exercendo um papel primordial na produção de etanol, biomassa e açúcar (WACLAWOSKY et al., 2010). Para cana e demais culturas, o fósforo (P) é considerado um elemento chave nos processos fisiológicos, como alongamento celular, transporte de energia, transdução de sinal, fotossíntese e respiração celular (KHAN et al., 2014; TAIZ et al., 2017).

Devido às baixas concentrações de $\mathrm{P}$ disponíveis nos solos, os fertilizantes fosfatados são altamente utilizados e resultam no esgotamento das reservas de suas rochas não renováveis (CORDELL et al., 2009; OBERSTEINER et al., 2013). Outro problema é que solos podem rapidamente imobilizar o fósforo fertilizado, devido à alta reatividade com óxidos e hidróxidos de ferro (Fe) e alumínio (Al), o que acarreta em um grande estoque de P indisponível no solo (RISKIN et al., 2013; RODRIGUES et al., 2016; ROY et al., 2016).

Wang et al. (2010) mostram que para aquisição de $P$ as características das raízes são fundamentais e que as plantas para obter um maior incremento podem sacrificar carboidratos para aquisição de nutrientes ou investirem em crescimento radicular. $\mathrm{A}$ troca de $\mathrm{P}$ por carboidratos é realizada pelas micorrizas, uma estratégia de associação com fungos que permiti uma maior exploração do solo e acesso a nutrientes antes indisponíveis (BAUM et al., 2015; YANG et al., 2015). Outra possibilidade de aquisição de P são as fosfatases, enzimas capazes de extrair grupamentos fosfato de fontes orgânicas (VENTERINK et al., 2010), sendo relatada como mantedora das leguminosas em ambientes limitados por P (VENTERINK, 2011). Assim, a compreensão e estudo dessas estratégias se tornam primordiais frente a futura crise de $\mathrm{P}$ e a grande quantidade que está retida e indisponível pelo solo (RODRIGUES et al., 2016).

Os Hormônios brassinoesteroides demostram de maneira benéfica atuar sobre os órgãos vegetais impulsionando os processos que os mesmos desenvolvem, como crescimento radicular, associação com fungos micorrízicos e a fotossíntese, processos esses intimamente ligados ao P (BITTERLICH et al., 2014; LV et al., 2018; MCGUINESS et al., 2019; WEl et al., 2016). Através da fotossíntese as plantas conseguem por um série de reações energia química (TAIZ et al., 2017), onde estudos mostram que a aplicação dos BR atenuam esse processo pelo incremento na assimilação líquida de $\mathrm{CO}_{2}$ e biomassa das plantas (JIANG et al., 2012).

Assim, a aplicação exógena de análogos de BR tornou-se alvo de pesquisas visando ao incremento de produção agrícola, como em abacaxi (FREITAS et al., 2012), no qual o análogo de BR desencadeou efeitos positivos nas características vegetativas da parte aérea das mudas e em arroz onde houve o benefício no crescimento radicular e aéreo (LARRÉ et al., 2014). Na cultura do tomate, mostrou haver uma interferência sobre fungos micorrízicos pela importância sobre o transportador de sacarose SISUT2, composto envolvido diretamente na manutenção da associação (BITTERLICH et al., 2014).

Evidências indicam que os BR são importantes reguladores do desenvolvimento radicular, mas há, ainda, uma grande lacuna sobre seus efeitos com P sobre crescimento, fosfatase, associações micorrízicas e fotossíntese em grandes culturas na fase inicial, como a cana-de-açúcar. A hipótese do presente estudo é que a aplicação do análogo na forma do 24-epibrassinolide associado à adubação fosfatada possa 
incrementar o desenvolvimento inicial das plantas de cana-de-açúcar, atuando no metabolismo por meio do acúmulo da matéria vegetal em decorrência de um incremento fotossintético. Visa-se a obtenção de dados iniciais que possam contribuir em relação a associação com micorrizas e atividade de fosfatase da cana-deaçúcar, como alternativa para mitigar a crise do P. Portanto, o objetivo deste estudo foi avaliar o efeito da aplicação de brassinoesteroides na presença ou ausência de fósforo, sobre o crescimento, a atividade de fosfatase ácida, associações micorrízicas e fotossíntese da cana-de-açúcar nas suas fases iniciais de crescimento e desenvolvimento.

\section{MATERIAIS E MÉTODOS}

O experimento foi realizado em casa de vegetação na Faculdade de Ciências Agrárias e TecnológicasFCAT/UNESP, localizada no Município de Dracena, Estado de São Paulo. A coleta do solo foi realizada em 05/10/2018, em uma área de Cerrado em Selvíria-MS.

O solo da área foi classificado como Latossolo Vermelho Distrófico, textura argilosa (SANTOS et al., 2018). Após a análise nutricional do solo, os atributos foram determinados, segundo a metodologia descrita por Raij et al. (2001), o qual apresentou os seguintes resultados: $2,0 \mathrm{mg} \mathrm{dm}^{-3} \mathrm{P}$ (resina); $22,0 \mathrm{~g} \mathrm{dm}^{-3}$ matéria orgânica; 5,0 mg dm${ }^{-3} \mathrm{~S}_{-} \mathrm{SO}_{4} ; 4,1 \mathrm{de} \mathrm{pH}\left(\mathrm{CaCl}_{2}\right) ; \mathrm{K}, \mathrm{Ca}, \mathrm{Mg}, \mathrm{H}+\mathrm{Al}=0,9 ; 3,0 ; 3,0$ e 58,0 mmolc dm $\mathrm{m}^{-3}$, respectivamente; $\mathrm{B}, \mathrm{Cu}, \mathrm{Fe}, \mathrm{Mn}, \mathrm{Zn}=0,13 ; 1,8 ; 33,0 ; 15,0$ e $0,2 \mathrm{mg} \mathrm{dm}^{-3}, \mathrm{CTC}=64,9 \mathrm{mmolc} \mathrm{dm}^{-3}$ e $11 \%$ de saturação por bases.

Foram utilizadas mudas pré-brotadas (MPB) da variedade RB 966928, com 40 dias de formação, fornecidas pelo viveiro credenciado do IAC-APTA de Ribeirão Preto-SP. As mudas foram transplantadas para vasos de 25 litros no dia 08/10/2018. O preparo do solo para o transplante foi baseado nas exigências da cultura da cana-de-açúcar (RAlJ et al., 1997), sendo adicionados, em cada vaso, 70 g de calcário dolomítico, 3,2 g de nitrogênio na forma de ureia e 5,9 g de cloreto de potássio.

O delineamento experimental adotado foi em blocos casualizados em esquema fatorial $4 \times 2$, o primeiro fator constituiu-se pelas doses de brassinoesteroides $\left(0,0 ; 0,5 ; 1,0\right.$ e $\left.2,0 \mathrm{mg} . \mathrm{L}^{-1}\right)$ e o segundo fator pela presença ou ausência de adubação fosfatada. Foram utilizadas 6 repetições, tendo assim 48 parcelas experimentais.

As parcelas sob presença de fósforo receberam 5,2 g de Superfosfato Simples $\left(\mathrm{P}_{2} \mathrm{O}_{5}\right)$ em cada vaso. Após o estabelecimento das mudas, ou seja, dez dias após o transplante (18/10/2018) para o vaso, foi realizada a aplicação dos tratamentos com brassinoesteroides. Foi utilizado o análogo $\left(\mathrm{C}_{28} \mathrm{H}_{48} \mathrm{O}_{6}\right)$ conhecido como 24-epibrassinolide da marca comercial SIGMA ${ }^{\circledR}$, dissolvido em etanol e dimetil sulfóxido para obtenção da solução estoque, posteriormente diluída em água destilada para as concentrações, de acordo com as doses adotadas. Foi aplicado um volume de $5,0 \mathrm{ml}$ da solução do modo que foi possível uma cobertura completa das mudas pela calda.

Trinta dias após a aplicação das doses de BR (18/11/2018), foi realizada uma análise fisiológica a fim de que fossem mensurados parâmetros fotossintéticos. As medições foram realizadas na região mediana da Folha +1 , completamente expandida, totalmente exposta à radiação solar no período compreendido entre 
às $10 \mathrm{~h} 00 \mathrm{~min}$ às $14 \mathrm{~h} 00 \mathrm{~min}$. Para tanto, foi utilizado um equipamento portátil de trocas gasosas, (Infra Red Gas Analyser -IRGA, marca ADC BioScientific Ltd, modelo LC-Pro). As condições inicialmente impostas para realização das medidas constaram de $1000 \mu \mathrm{mol} \mathrm{m}^{-2} \mathrm{~s}^{-1}$ de radiação fotossinteticamente ativa (PAR), providas por lâmpadas LED; $380 \mathrm{ppm}$ de $\mathrm{CO}_{2}$ e temperatura da câmara em $28^{\circ} \mathrm{C}$. Foram avaliadas as seguintes características: taxa de assimilação líquida de $\mathrm{CO}_{2}\left(\mu \mathrm{mol} \mathrm{m} \mathrm{m}^{-2} \mathrm{~s}^{-1}\right)$; condutância estomática $\left(\mathrm{mol} \mathrm{m}^{-2} \mathrm{~s}^{-1}\right)$; concentração interna de $\mathrm{CO}_{2}\left(\mu \mathrm{mol} \mathrm{m} \mathrm{m}^{-2}\right)$; taxa de transpiração nas folhas $\left(\mathrm{mmol} \mathrm{m} \mathrm{m}^{-2} \mathrm{~s}^{-1}\right)$ e temperatura interna da folha $\left({ }^{\circ} \mathrm{C}\right)$. A eficiência do uso da água $\left(\mu \mathrm{mol} \mathrm{mmol}{ }^{-1}\right)$ foi mensurada de acordo com a relação entre a assimilação líquida de $\mathrm{CO}_{2}$ e os valores de transpiração da folha (DONOVAN et al., 1994).

O experimento foi encerrado no dia 23/12/2018 com 75 dias após o transplante. Nessa ocasião, as massas radicular e aérea foram levadas à estufa de circulação a $60 \circ C$ durante 72 horas para secagem e posterior pesagem em balança de precisão. Através da somatória da massa dos pesos secos dessas regiões, a massa seca total da planta foi obtida.

Uma amostra de $130 \mathrm{mg}$ de raiz foi coletada e enviada para o laboratório de Ecologia Vegetal da Unesp de Ilha Solteira-FEIS, onde foi determinada a atividade de fosfatase ácida radicular, seguindo o protocolo do nitrofenil-fosfato (adaptado de VENTERINK, 2011) e determinação de colonização micorrízica, seguindo o protocolo de Vierheilig et al. (1998).

De acordo com o software SISVAR (FERREIRA, 2014), a hipótese da normalidade foi testada pelo teste de Shapiro-Wilk. Foi realizada a análise de variância (ANAVA), sendo aplicado o teste $F$ a $5 \%$ de probabilidade. Para as doses aplicadas foi realizada a análise de variância na regressão.

\section{RESULTADOS}

A massa seca radicular (MSR), massa seca aérea (MSA) e massa seca total (MST) aumentaram significativamente em resposta à adição de fósforo (Tabela 1). O tratamento $B R$, isoladamente, afetou significativamente MSR, a qual não respondeu à interação entre os fatores. Já os valores de MSA e MST não responderam significativamente às doses do hormônio isoladamente. Porém, foi verificado um efeito da interação entre P e BR sobre MSA.

Tabela 1: Valores de massa seca radicular (MSR), aérea (MSA) e total (MST) em g/planta aos 75 dias após à aplicação das doses de brassinoesteroides (BR), sobre a presença ou ausência do elemento fósforo (P).

\begin{tabular}{|c|c|c|c|c|}
\hline & & MSR & MSA & MST \\
\hline \multirow{2}{*}{$P$} & Presença & $184,54 \mathrm{a}$ & $104,20 \mathrm{a}$ & $298,16 a$ \\
\hline & Ausência & $144,54 \mathrm{~b}$ & $78,23 \mathrm{~b}$ & $222,32 \mathrm{~b}$ \\
\hline \multirow{4}{*}{$B R$} & 0 & $115,06 \mathrm{~b}$ & $82,19 a$ & $216,08 \mathrm{a}$ \\
\hline & 0,5 & 197,18 a & $87,58 \mathrm{a}$ & $284,73 a$ \\
\hline & 1 & $169,36 \mathrm{ab}$ & $100,76 \mathrm{a}$ & $270,12 \mathrm{a}$ \\
\hline & 2 & $175,64 a b$ & 94,39 a & $270,03 a$ \\
\hline \multirow{4}{*}{ Teste F } & Bloco & $1,725^{\mathrm{ns}}$ & $2,805^{*}$ & $2,058^{\text {ns }}$ \\
\hline & $\mathrm{P}$ & $5,946^{*}$ & $13,502^{* *}$ & $10,394^{* *}$ \\
\hline & $\mathrm{BR}$ & $4,433^{* *}$ & $1,309^{n s}$ & $1,653^{\mathrm{ns}}$ \\
\hline & $P \times B$ & $0,660^{n s}$ & $3,797^{*}$ & $0,799^{\text {ns }}$ \\
\hline Média Geral & & 164,31 & 91,22 & 260,24 \\
\hline CV (\%) & & 34,97 & 26,84 & 31,31 \\
\hline
\end{tabular}

Nota: $* *, * \mathrm{e}^{\mathrm{ns}}$, significativo a $1 \%, 5 \%$ e não-significativo, respectivamente, pelo Teste $\mathrm{F}$. Médias seguidas pela mesma letra não diferem entre si nas colunas pelo teste de Tukey a $5 \%$. 
Ressalta-se que a dose $0,5 \mathrm{mg} \cdot \mathrm{L}^{-1}$ de brassinoesteroides refletiu no melhor desenvolvimento das raízes. Ao derivar a regressão aponta para o ponto máximo da curva em 1,27 mg. L-1 (Figura 1).

A regressão quadrática apresentou o melhor ajuste ao conjunto de dados da variável MSA. De acordo com o desdobramento, devido a interação entre os fatores, foi observado que os melhores resultados foram obtidos nas doses de 0,5 e 1,0 mg. $\mathrm{L}^{-1}$ de brassinoesteroides na presença de fósforo (Tabela 2).

Tabela 2: Médias de massa seca aérea (MSA) resultantes da interação entre doses de brassinoesteroides (BR) na presença ou ausência de fósforo (P).

\begin{tabular}{|c|c|c|c|c|c|}
\hline & & \multicolumn{4}{|c|}{ Brassinoesteroides } \\
\hline & & $0^{\text {ns }}$ & $0,5^{*}$ & $1,0^{* *}$ & $2,0^{\text {ns }}$ \\
\hline \multirow{2}{*}{ Fosforo } & Presença** & $80,25 \mathrm{a}$ & $103,34 a$ & 131,54 a & 101,09 a \\
\hline & Ausência ns & $83,25 \mathrm{a}$ & $71,24 \mathrm{~b}$ & $69,99 \mathrm{~b}$ & 87,69 a \\
\hline
\end{tabular}

Nota: $* *, e^{\mathrm{ns}}$, significativo a $1 \%, 5 \%$ e não-significativo, respectivamente, pelo Teste $\mathrm{F}$. Médias seguidas pela mesma letra não diferem entre si nas colunas pelo teste $\mathrm{F}$ a $5 \%$.

A regressão quadrática proporcionou o melhor ajuste ao desdobramento da interação massa seca aérea sobre a presença ou ausência de fósforo em relação às doses de brassinoesteroides, e coeficiente de determinação de 92,46\% (Figura 2), com uma correlação de Pearson de 96,15\%. Foi verificado um comportamento crescente da curva até seu ponto máximo de 1,16 mg. $\mathrm{L}^{-1}$ na presença do fósforo (Figura 2).

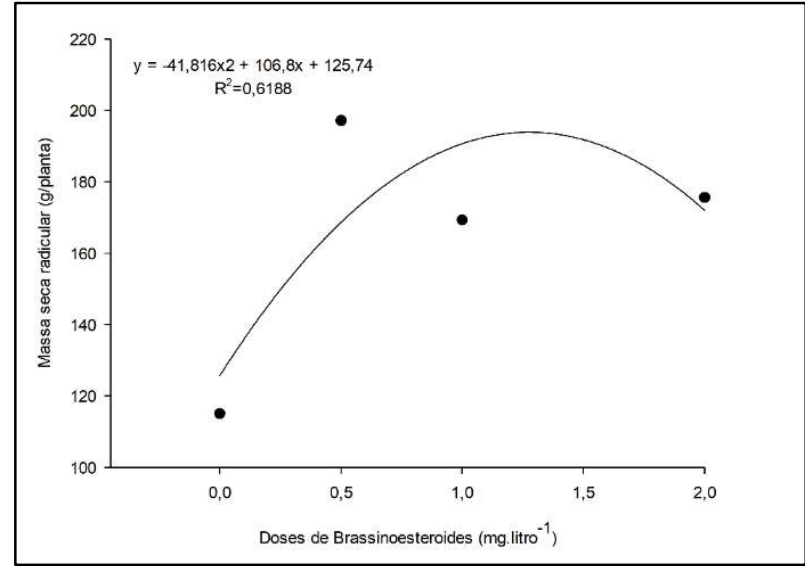

Figura 1: Massa seca radicular (MSR) de cana-de-açúcar em função da aplicação das doses de brassinoesteroides aos 75 dias após o transplantio.

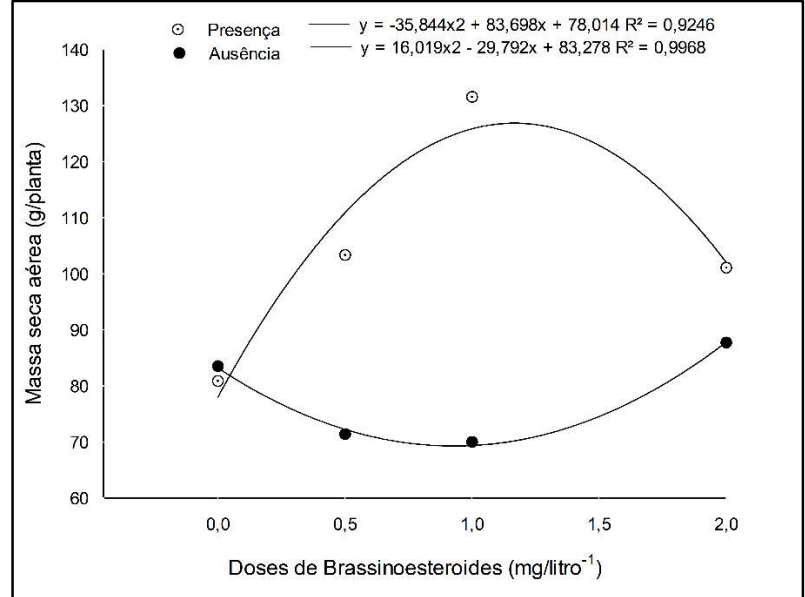

Figura 2: Desdobramento da interação brassinoesteroides na presença ou ausência de fósforo sobre a massa seca aérea aos 75 dias após o transplantio.

A adição de fósforo não afetou significativamente atividade de fosfatase ácida e colonização micorrízica. As doses de brassinoesteroides, entretanto, influenciaram na atividade dessa enzima, segundo apontado na Tabela 3. A aplicação do hormônio vegetal na dose de 1,0 $\mathrm{mg} \mathrm{L}^{-1}$ desencadeou um aumento na atividade de fosfatase ácida da planta (Tabela 3; Figura 3).

Aos 30 dias após transplantio, as variáveis temperatura interna da folha (Co), concentração interna de $\mathrm{CO}_{2}$ e eficiência do uso da água não demonstraram diferença estatística em relação à aplicação dos tratamentos. A adição de fósforo acarretou incrementos significativos nas variáveis transpiração da folha $(p<0,05)$, condutância estomática $(p<0,01)$ e assimilação líquida de $\mathrm{CO}_{2}(p<0,01)$ (Tabela 4). 
Tabela 3: Análise de variância para atividade de fosfatase ácida radicular (PME) e quantificação da porcentagem de colonização micorrízica de cana-de-açúcar, na presença ou ausência do elemento fósforo e aplicação de doses do hormônio brassinoesteroides.

\begin{tabular}{llll}
\hline & & PME $(\mu \mathrm{g}$ de p-nitrofenol g-1 raiz) & Micorriza (\%) \\
\hline $\mathrm{P}$ & Presença & $8440,08 \mathrm{a}$ & $55,40 \mathrm{a}$ \\
& Ausência & $7519,14 \mathrm{a}$ & $57,79 \mathrm{a}$ \\
\hline \multirow{3}{*}{$\mathrm{BR}$} & 0 & $7523,46 \mathrm{ab}$ & $55,99 \mathrm{a}$ \\
& 0,5 & $6686,59 \mathrm{~b}$ & $52,04 \mathrm{a}$ \\
& 1 & $10241,16 \mathrm{a}$ & $53,74 \mathrm{a}$ \\
\hline & 2 & $7467,23 \mathrm{ab}$ & $64,59 \mathrm{a}$ \\
\hline \multirow{2}{*}{ Teste F } & Bloco & $1,668^{\text {ns }}$ & $0,77^{\text {ns }}$ \\
& $\mathrm{P}$ & $1,535^{\text {ns }}$ & $0,288^{\text {ns }}$ \\
& BR & $4,377^{*}$ & $1,554^{\text {ns }}$ \\
\hline Média Geral & $\mathrm{Px} \mathrm{B}$ & $0,949^{\text {ns }}$ & $0,495^{\text {ns }}$ \\
\hline
\end{tabular}

Nota: ${ }^{* *},{ }^{*} \mathrm{e}^{\mathrm{ns}}$, significativo a $1 \%, 5 \%$ e não-significativo, respectivamente, pelo Teste $\mathrm{F}$. Médias seguidas pela mesma letra não diferem entre si nas colunas pelo teste de Tukey a $5 \%$.

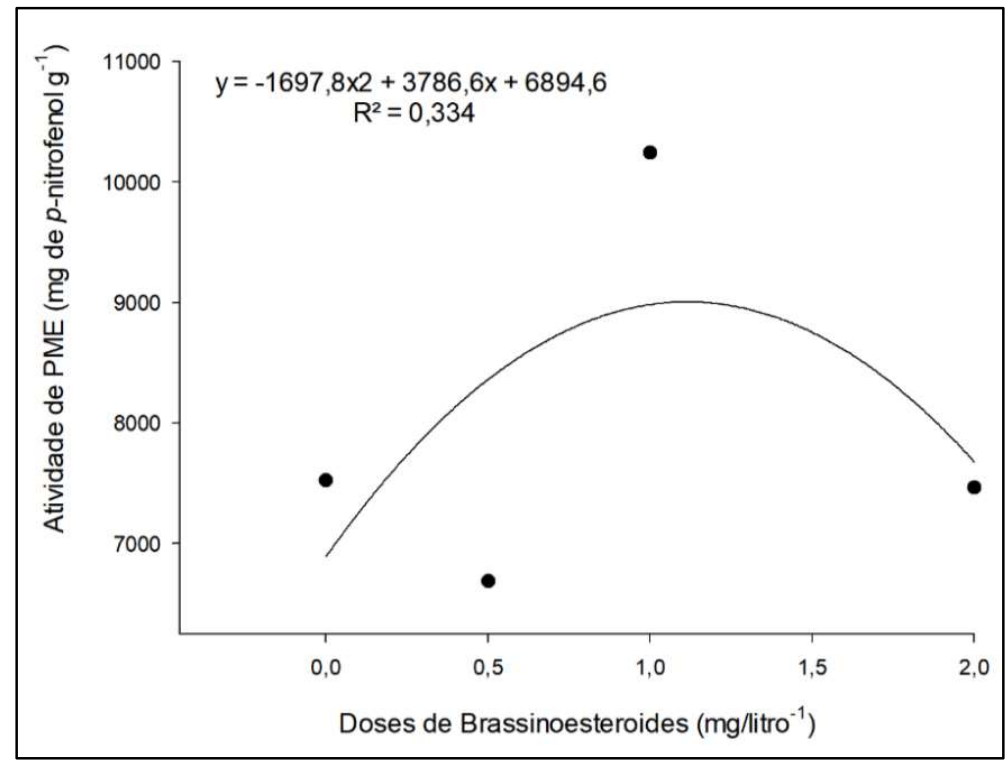

Figura 3: Atividade de fosfatase ácida das raízes em relação à aplicação das doses de brassinoesteroides aos 75 dias após o transplantio.

Tabela 4: Análise de variância dos parâmetros fotossintéticos, sendo temperatura interna da folha (TLEAF), concentração interna de $\mathrm{CO}_{2}(\mathrm{Cl})$, Taxa de transpiração da folha (E), condutância estomática (GS), assimilação liquida de $\mathrm{CO}_{2}(\mathrm{~A})$ e eficiência do uso da água (EUA).

\begin{tabular}{|c|c|c|c|c|c|c|c|}
\hline & & TLEAF & $\mathrm{Cl}$ & $\mathrm{E}$ & GS & $\mathrm{A}$ & EUA \\
\hline \multirow{2}{*}{$P$} & Presença & $38,662 \mathrm{a}$ & $273,50 a$ & $2,710 \mathrm{a}$ & $0,071 \mathrm{a}$ & $10,27 \mathrm{a}$ & $3,44 \mathrm{a}$ \\
\hline & Ausência & 39,312 a & $124,54 \mathrm{a}$ & $2,197 \mathrm{~b}$ & $0,053 \mathrm{~b}$ & $7,709 \mathrm{~b}$ & $3,529 a$ \\
\hline \multirow{4}{*}{ BR } & 0 & $39,375 \mathrm{a}$ & $148 a$ & $2,385 \mathrm{a}$ & $0,057 \mathrm{a}$ & $7,48 \mathrm{a}$ & $3,114 \mathrm{a}$ \\
\hline & 0,5 & 39,208 a & $111 \mathrm{a}$ & $2,545 \mathrm{a}$ & $0,065 a$ & 9,556 a & $3,745 \mathrm{a}$ \\
\hline & 1 & 39,175 a & $122 \mathrm{a}$ & $2,67 \mathrm{a}$ & 0,069 a & 9,409 a & $3,619 \mathrm{a}$ \\
\hline & 2 & $38,191 \mathrm{a}$ & $114 a$ & $2,217 \mathrm{a}$ & 0,058 a & 9,518 a & $3,47 \mathrm{a}$ \\
\hline \multirow{4}{*}{ Teste F } & Bloco & $2,887^{*}$ & $1,476^{\text {ns }}$ & $1,639^{\text {ns }}$ & $1,270^{\text {ns }}$ & $2,366^{*}$ & $2,792^{*}$ \\
\hline & $\mathrm{P}$ & $1,447^{\text {ns }}$ & $0,012^{\text {ns }}$ & $4,931^{*}$ & $7,847^{* *}$ & $9,374^{* *}$ & $0,091^{\text {ns }}$ \\
\hline & BR & $0,990^{\text {ns }}$ & $1,305^{\mathrm{ns}}$ & $0,722^{\text {ns }}$ & $0,795^{\text {ns }}$ & $1,454^{\mathrm{ns}}$ & $0,987^{n s}$ \\
\hline & $\mathrm{P} \times \mathrm{B}$ & $0,621^{\text {ns }}$ & $1,001^{\mathrm{ns}}$ & $0,389^{\text {ns }}$ & $0,670^{\text {ns }}$ & $3,193^{*}$ & $0,358^{\text {ns }}$ \\
\hline Média Geral & & 38,987 & 123,75 & 2,454 & 0,062 & 8,99 & 3,487 \\
\hline CV (\%) & & 4,8 & 41,21 & 32,6 & 34,63 & 32,25 & 27,31 \\
\hline
\end{tabular}

Nota: $* * * e^{\mathrm{ns}}$, significativo a $1 \%, 5 \%$ e não-significativo, respectivamente, pelo Teste $\mathrm{F}$. Médias seguidas pela mesma letra não diferem entre si nas colunas pelo teste de Tukey a $5 \%$.

A adição de fósforo e de brassinoesteroides em conjunto influenciaram na assimilação líquida de $\mathrm{CO}_{2}$. Para essa variável, a maior dose do hormônio na presença de fósforo proporcionou uma maior taxa 
fotossintética para as plantas (Tabela 5).

Tabela 5: Médias de Assimilação liquida de $\mathrm{CO}_{2}\left(\mu \mathrm{mol} \mathrm{m}^{-2} \mathrm{~s}^{-1}\right)$, para interação das doses de brassinoesteroides (BR) na presença ou ausência de fósforo $(\mathrm{P})$

Assimilação Liquida de $\mathrm{CO}_{2}$

\begin{tabular}{llllll}
\hline & \multicolumn{3}{l}{ Brassinoesteróides } & & \\
\multirow{3}{*}{ Fosforo } & $0^{\text {ns }}$ & $0,5^{\text {ns }}$ & $1,0^{\text {ns }}$ & $2,0^{* *}$ \\
& Presença* $^{*}$ & $7,92 \mathrm{a}$ & $10,21 \mathrm{a}$ & $9,92 \mathrm{a}$ & $13,04 \mathrm{a}$ \\
& Ausêncians $^{*}$ & $7,03 \mathrm{a}$ & $8,91 \mathrm{a}$ & $8,89 \mathrm{a}$ & $5,99 \mathrm{~b}$ \\
\hline
\end{tabular}

Nota: ${ }^{* *},{ }^{*} \mathrm{e}^{\mathrm{ns}}$, significativo a $1 \%, 5 \%$ e não-significativo, respectivamente, pelo Teste $\mathrm{F}$. Médias seguidas pela mesma letra não diferem entre si nas colunas pelo teste de Tukey a $5 \%$.

A regressão linear mostrou melhor ajuste ao desdobramento da interação (P e BR) sobre a variável de assimilação liquida de $\mathrm{CO}_{2}$, como mostra a figura 4 .

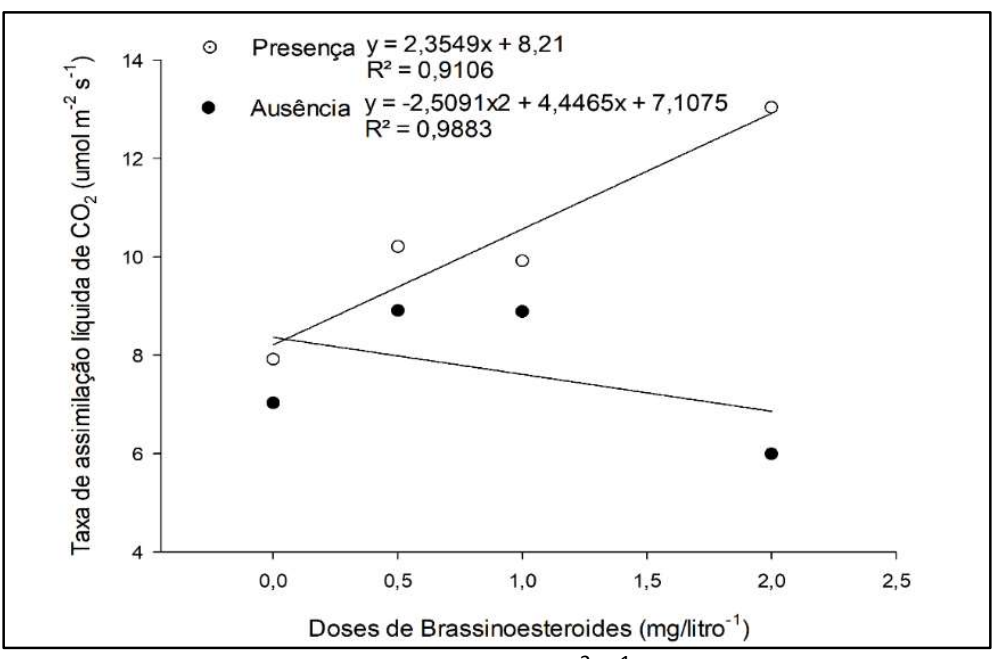

Figura 4: Desdobramento da Assimilação liquida de $\mathrm{CO}_{2}\left(\mu \mathrm{mol} \mathrm{m}^{-2} \mathrm{~s}^{-1}\right)$ em função da ausência ou presença de fósforo e a aplicação das doses de brassinoesteroides aos 30 dias após o transplantio.

\section{DISCUSSÃO}

A sobrevivência e o desenvolvimento das plantas são dependentes de um sistema radicular vigoroso, o que reflete numa melhor captação de água e nutrientes (WEI et al., 2016). Neste estudo, observou-se uma resposta positiva da massa seca radicular da cana-de-açúcar à presença do fósforo e brassinoesteroides. Estudos como de Larré et al. (2014) demonstram os efeitos benéficos similares desencadeados pela adição do 24-epibrassínolideo no cultivo de arroz, constatando que a adição de doses de 0,1 e 1,0 $\mu \mathrm{M}$ aumentaram o sistema radicular de suas plantas e beneficiaram as mesmas. Em cevada, a adição do hormônio na dose de 1,0 $\mu \mathrm{M}$ praticamente dobrou o crescimento radicular quando comparado ao tratamento controle, associando este efeito com o aumento constatado da atividade mitótica do órgão (KARTAL et al., 2009).

As respostas à adição dos brassinoesteroides possuem um comportamento dose dependente, no qual pequenas doses estimulam o desenvolvimento do sistema radicular e altas doses inibem este crescimento, baseados nos estudos realizados com modelos de Arabidopsis thaliana (GOMES, 2011; GONZÁLES et al., 2011; HACHAM et al., 2011; CHAIWANON et al., 2015; GUPTA et al., 2015; LEE et al., 2015). Os dados desta pesquisa seguem este padrão até então não apresentados nesta cultura, onde somente a dose $0,5 \mathrm{mg}$. $\mathrm{L}^{-1}$ apresentou resultados significativos. 
Nas variáveis massa seca radicular, massa seca aérea e massa seca total nota-se a importância do fósforo. Tendo em vista que os solos brasileiros no geral são pobres em fósforo (DUARTE et al., 2015; SILVA et al., 2015), entende-se que, nessas condições, a adição do mesmo tenha aliviado a limitação nutricional. 0 solo utilizado neste estudo foi oriundo de uma área de Cerrado, bioma especificamente conhecido pela carência nutricional de fósforo, à qual é limitante para o desenvolvimento de algumas espécies que vivem no mesmo (LANNES et al., 2016). Diversos estudos relatam o efeito benéfico da adição de fosforo sobre a biomassa na cultura da cana-de-açúcar (ALBUQUERQUE et al., 2016; LISBOA et al., 2017; BORGES et al., 2019; GUMIERE et al., 2019; SOLTANGHEISI et al., 2019) e que sua falta acarreta grandes prejuízos (SIMÕES NETO et al., 2015). Esse efeito significativo da presença do P sobre a massa seca da planta pode ser compreendido pela importância do mesmo em diversas substâncias estruturais, como proteínas da parede celular, lipídios, açúcares, dentre outras que servem de fonte de energia para o crescimento vegetal (TAIZ et al., 2017).

Esta pesquisa é, provavelmente, a primeira demostrar o efeito sinérgico entre o BR e $P$ sobre a massa seca área de plantas de cana-de-açúcar. Os resultados encontrados podem ser explicados por uma resposta causada pelo incremento ocasionado pelos elementos separadamente sobre massa seca radicular e o efeito sinérgico sobre a variável de assimilação líquida de $\mathrm{CO}_{2}$. Vale destacar que outros autores obtiveram este incremento ao adotarem a adição do referido hormônio em suas pesquisas. Freitas et al. (2012) constataram que a adição do 24-epibrassínolideo no cultivo do abacaxizeiro na dosagem de $1,0 \mathrm{mg} \cdot \mathrm{L}^{-1}$ desencadeou um incremento sobre a biomassa seca da parte aérea. Zhang et al. (2013) relatam que a aplicação do brassinoesteroides na dosagem de 1,0 mg. $\mathrm{L}^{-1}$ foi benéfica sobre as variáveis de biomassa seca área e radicular em melão, minimizando os efeitos ocasionados pelo estresse por altas temperaturas. Da mesma forma, a aplicação do 24 epibrassinolideo em pepino aumentou de 20,06 para 22,6\% a área foliar e acumulo de biomassa da parte aérea (JIANG et al., 2012).

A atividade da fosfatase ácida não é constante nas plantas. Além disso, essa enzima é influenciada pelas condições ambientais do solo, principalmente pelas variações de N e P (VENTERINK, 2011). Geralmente a atividade de fosfatase da raiz aumenta em resposta à baixa disponibilidade de $\mathrm{P}$ no solo ou alta disponibilidade de N (FUJITA et al., 2010; VENTERINK et al., 2010). Assim, a correção de N realizada no solo na forma de ureia pode explicar a não significância entre o tratamento com fósforo e o tratamento controle, uma vez que o solo foi devidamente corrigido. Ainda, a adição deste elemento visou o suprimento da necessidade da planta, baseado no incremento encontrados nas variáveis de massa seca e fotossíntese.

Sendo assim, a adição do hormônio vegetal resultou em um aumento da atividade de fosfatase ácida, o que pode ser explicado pelo efeito do mesmo sobre crescimento radicular da planta, baseado nos valores significativos de BR sobre o crescimento aéreo. A aplicação, tanto do fósforo, como do hormônio vegetal não demonstrou efeito significativo sobre a porcentagem de colonização micorrízica nas plantas estudadas.

As associações micorrízicas são benéficas às plantas pela troca entre nutrientes e carbono (NOURI et al., 2014). Essas associações são influenciadas por múltiplos fatores, como a intensidade da limitação, o tipo de limitação ( $\mathrm{N}$ ou $\mathrm{P}$ ), o investimento necessário de carbono pela planta e a origem dos fungos (locais vs não locais) (JOHNSON et al., 2010). O fato da adição de fósforo não ter desencadeado um aumento na colonização 
micorrízica pode ser explicado pelo fornecimento do P nos vasos, sendo o investimento nas micorrizas uma desvantagem devido à oferta e pelo custo do carbono se tornar mais caro para planta, já que as mesmas tiveram na presença do fósforo o nutriente facilmente disponível (SOKA et al., 2014). A presente pesquisa demonstrou que as plantas de cana-de-açúcar em sua fase inicial investiram o déficit de P sobre crescimento de raiz (baseado nos valores apresentados na Análise de Variância) ao invés de associação com fungos micorrízicos (HALING et al., 2016).

Gumiere et al. (2019), estudando os efeitos de fontes de fósforo nas interações microbianas do solo de cana-de-açúcar, demonstraram que a adição das fontes de superfosfato simples $\left(18 \%\right.$ de $\left.\mathrm{P}_{2} \mathrm{O}_{5}\right)$, fosfato de rocha Catalão $\left(2,93\right.$ de $\left.\mathrm{P}_{2} \mathrm{O}_{5}\right)$ e fosfato de rocha Bayovar $\left(14 \%\right.$ de $\left.\mathrm{P}_{2} \mathrm{O}_{5}\right)$ desencadearam efeitos antagonistas sobre a colonização da cana-de-açúcar. A utilização da fonte com maior concentração de $P$ (superfosfato simples), ocasionou em maior teor de matéria seca total e atividade bacteriana no solo em seu estudo. Porém, com a adição de micorrizas houve uma redução na matéria seca total. Assim, esse resultado pode ser associado ao presente estudo, ou o a fertilização suprindo a vantagem da colonização micorrízica (SOKA et al., 2014).

Poucos trabalhos abordam a adição de brassinoesteroides sobre as associações micorrízicas. No entanto, Bitterlich et al. (2014) demostraram que tomates mutantes apresentaram uma deficiência na biossíntese de brassinoesteroides, o que ocasionou uma micorrização diminuída e redução do conteúdo de açúcares elaborados. Como os açúcares servem de energia para manutenção da associação, sugere-se uma possível intervenção de BR na infecção e colonização das micorrizas.

Foo et al. (2013) demostraram que mutantes de ervilha deficientes em giberelinas, proteínas DELLA e brassinoesteroides não apresentaram alterações na colonização, supondo assim, que se esta classe de hormônios estiver envolvida nesta espécie, mudanças grandes nos seus níveis seriam necessárias.

As respostas benéficas nas variáveis de transpiração, condutância estomática e assimilação liquida de $\mathrm{CO}_{2}$ da fotossíntese à adição de $\mathrm{P}$ permitem que as plantas por meio de reações metabólicas obtenham a energia necessária para o seu crescimento e desenvolvimento (FERREIRA et al., 2019). Silva et al. (2010) demostraram que mudas de café arábica (Coffea arabica) submetidas à dosagem ideal de $\mathrm{P}$, e também duas vezes essa dosagem, apresentaram um incremento na assimilação liquida de $\mathrm{CO}_{2}$ e condutância estomática, refletindo em maior produção de matéria seca.

A assimilação liquida de $\mathrm{CO}_{2}$ representa a taxa de fotossíntese liquida da planta em resposta ao aproveitamento da energia luminosa, sendo o tanto que a planta aproveita da energia que recebe do sol (FERRAZ et al., 2014). A interceptação da luz solar é um fator importante, responsável para a obtenção do máximo de produtividade das culturas agrícolas (NOBERTO et al., 2018). Uma vez que a abertura dos estômatos permite uma maior entrada de $\mathrm{CO}_{2}$ nos sítios de carboxilação da Rubisco, o efeito sobre a variável de assimilação e condutância estomática é entendido (DALLAGNOL et al., 2011; PINHEIRO et al., 2011; RODRIGUES et al., 2011).

Existem somente relatos sobre os benefícios da adição de BR separadamente sobre a fotossíntese, como apresentado sobre a influência em mutantes de tomate em que os BR são atenuante das enzimas do 
ciclo de Calvin-Benson, maximalizando os benefícios da fotossíntese por induzir a planta a um status redox (Ll et al., 2016). Em outro estudo com tomate, a aplicação dos BR (1 $\mu \mathrm{M})$ minimizou os efeitos deletérios do estresse por salinidade, causando uma melhora nas variáveis relacionadas à condutância estomática, assimilação liquida de $\mathrm{CO}_{2}$ e conteúdo intercelular (AHANGER et al., 2020).

Em geral, os dados obtidos neste trabalho suportam esses resultados, ressaltando os efeitos inéditos sobre o desenvolvimento inicial da cana-de-açúcar. A adição de $P$ exerceu uma influência positiva sobre a fotossíntese. A combinação com BR resultou em um incremento da assimilação líquida de $\mathrm{CO}_{2}$. Os resultados ocasionados pela combinação do 24-epibrassinolideo e fósforo são promissores. Entretanto são iniciais levantando várias questões a serem compreendida para potencializar a fertilização das culturas, atividade de fosfatase e associações com as micorrizas visando um aproveitamento e aumento da produção.

\section{CONCLUSÕES}

Houve efeito positivo do nutriente fósforo e do hormônio vegetal brassinoesteroides sobre plantas de cana-de-açúcar, dando suporte à hipótese do presente estudo. Observou-se o efeito positivo sinérgico nas variáveis sobre massa seca aérea e fotossíntese.

A adubação fosfatada atuou incrementando os valores de crescimento, transpiração, condutância estomática e assimilação líquida de $\mathrm{CO}_{2}$. Por sua vez, os $\mathrm{BR}$ atuaram sobre massa seca radicular e atividade de fosfatase ácida.

\section{REFERÊNCIAS}

AHANGER, M. A.; MIR, R. A.; ALYEMENI, M. N.; AHMAD, P.. Combined effects of brassinosteroid and kinetin mitigates salinity stress in tomato through the modulation of antioxidant and osmolyte metabolism. Plant Physiology and Biochemistry, New Delhi, v.147, p.31-42, 2020. DOI: http://doi.org/10.1016/j.plaphy.2019.12.007

ALBUQUeRQUE, A. W.; SÁ, L. A.; RODRIGUES, W. A. R.; MOURA, A. B.; OLIVEIRA FILHO, M. S.. Growth and yield of sugarcane as a function of phosphorus doses and forms of application. Revista Brasileira de Engenharia Agrícola e Ambiental, Campina Grande, v.20, n.1, p.29-35, 2016. DOI: http://dx.doi.org/10.1590/1807-1929/agriambi.v20n1p29$\underline{35}$

BAUM, C.; EL-TOHAMY, W.; GRUDA, N.. Increasing the productivity and product quality of vegetable crops using arbuscular mycorrhizal fungi: A review. Scientia Horticulturae, Amsterdam, v.187, p.131-141, 2015. DOI: http://doi.org/10.1016/i.scienta.2015.03.002

BITTERLICH, M.; KRÜGEL, U.; BOLDT-BURISCH, K.; FRANKEN, P.; KÜHN, C.. The sucrose transporter SI SUT 2 from tomato interacts with brassinosteroid functioning and affects arbuscular mycorrhiza formation. The Plant Journal, London, v.78, n.5, p.877-889, 2014. DOI:

http://doi.org/10.1111/tpj.12515

BORCIONI, E.; NEGRELLE, R. R. B.. Aplicação de análogo de brassinosteroide (Biobras $16^{\circledR}$ ) sobre a germinação e crescimento in vitro de embriões zigóticos e aclimatização de plântulas de bocaiuva. Ciência Rural, Santa Maria, v.42, n.2, p.270-275, 2012. DOI: http://doi.org/10.1590/S010384782012000200014

BORGES, B. M. M. N.; ABDALA, D. B.; SOUZA, M. F.; VIGLIO, L. M.; COELHO, M. J. A.; PAVINATO, P. S.; FRANCO, H. C. J.. Organomineral phosphate fertilizer from sugarcane byproduct and its effects on soil phosphorus availability and sugarcane yield. Geoderma, Amsterdam, v.339, p.20-30, 2019. DOI: http://doi.org/10.1016/j.geoderma.2018.12.036

CHAIWANON, J.; WANG, Z.-Y.. Spatiotemporal brassinosteroid signaling and antagonism with auxin pattern stem cell dynamics in Arabidopsis roots. Current Biology, London, v.25, n.8, p.1031-1042, 2015. DOI: http://doi.org/10.1016/j.cub.2015.02.046

CORDEIRO, N. K.; SOUZA, D. H. G.; BERNARDI, D.; CARDOSO, K. P. S.; LAZARETTI, N .S.; ABRAÃO, P. C.; MATA, T. C.; JÚNIOR, E. K. M.. Analysis of regression and correlation on production of sugarcane in the States of Paraná, São Paulo and Minas Gerais, Brazil. Journal of Experimental Agriculture International, London, v.36, p.1-8, 2019. DOI: http://doi.org/10.9734/jeai/2019/v36i530246

CORDELL, D.; DRANGERT, J.-O.; WHITE, S.. The story of phosphorus: global food security and food for thought. Global Environmental Change, Guildford, v.19, n.2, p.292305, 2009. DOI: http://doi.org/10.1016/j.gloenvcha.2008.10.009 
DALLAGNOL, L. J.; RODRIGUES, F. A.; MARTINS, S. C. V; CAVATTE, p. C.; DAMATTA, F. M.. Alterations on rice leaf physiology during infection by Bipolaris oryzae. Australasian Plant Pathology, v.40, n.4, p.360-365, 2011. DOI: http://doi.org/10.1007/s13313-011-0048-8

DONOVAN, L. A.; EHLERINGER, J. R.. Carbon isotope discrimination, water-use efficiency, growth, and mortality in a natural shrub population. Oecologia, Berlin, v.100, n.3, p.347-354, 1994. DOI: http://doi.org/10.1007/BF00316964

DUARTE, C. F. D.; PAIVA, L. M.; FERNANDES, H. J.; PROCHERA, D. L.; CASSARO, L. H.; BREURE, M. F.; FLORES, L. S.; FERNANDES, R. L.; SOUZA, E. R. C.; FLEITAS, A. C.. Piata palisadegrass fertilized with different sources of phosphorus for solubility in water. Arquivo Brasileiro de Medicina Veterinária e Zootecnia, Belo Horizonte, v.67, n.1, p.315318, 2015. DOI: http://doi.org/10.1590/1678-7463

FERRAZ, R. L. S.; BELTRÃO, N. E. M.; MAGALHÃES, I. D.; FERNANDES, P. D.; ROCHA, M. S.. Trocas gasosas e eficiência fotoquímica de cultivares de algodoeiro herbáceo sob aplicação de silício foliar. Semina, v.35, n.2, p.735-748, 2014 DOI: DOI: http://10.5433/1679-0359.2014v35n2p735

FERREIRA, D. F.. Sisvar: a Guide for its Bootstrap procedures in multiple comparisons. Ciência e Agrotecnologia, Lavras, v.38, n.2, p.109-112, 2014. DOI: http://doi.org/10.1590/S1413-70542014000200001

FERREIRA, L.; RODRIGUES, M. G. F.; LISBOA, L. A. M.; SILVA, A. G.; SILVA, A. A. P.; FIGUEIREDO, P. A. M.. Photosynthetic characteristics in fig tree accessions for diversification of production. Revista Agro@mbiente, Boa Vista, v.13, p.268278, 2019. DOI: http://dx.doi.org/10.18227/19828470ragro.v13i0.5645

FERREIRA, N. S.; MATOS, G. F.; MENESES, C. H. S. G.; REIS, V. M.; ROUWS, J. R. C.; SCWAB, S.; BALDANI, J. L.; ROUWS L. F.. Interaction of phytohormone-producing rhizobia with sugarcane mini-setts and their effect on plant development. Plant and Soil, The Hague, p.1-18, 2020. DOI: http://doi.org/10.1007/s11104-019-04388-0

FOO, E.; ROSS, J. J.; JONES, W. T.; REID, J. B.. Plant hormones in arbuscular mycorrhizal symbioses: an emerging role for gibberellins. Annals of Botany, London, v.111, n.5, p.769779, 2013. DOI: http://doi.org/10.1093/aob/mct041

FREITAS, S. J.; SANTOS, P. C.; CARVALHO, A. J. C.; BERILLI, S. S.; GOMES, M. M. A.. Brassinosteroide e adubação nitrogenada no crescimento e estado nutricional de mudas de abacaxizeiro provenientes do seccionamento de caule. Revista Brasileira de Fruticultura, Cruz das Almas, v.34, n.2, p.612-618, 2012. DOI: http://doi.org/10.1590/S0100$\underline{29452012000200037}$

FUIITA, Y.; ROBROEK, B. J. M.; RUITER, P. C.; HEIL, G. W.; WASSEN, M. J.. Increased $N$ affects $P$ uptake of eight grassland species: the role of root surface phosphatase activity. Oikos, Buenos Aires, v.119, n.10, p.1665-1673, 2010. DOI: http://doi.org/10.1111/j.1600$\underline{0706.2010 .18427 . x}$

GOMES, M. M. A.. Physiological effects related to brassinosteroid application in plants. In: HAYAT, S.; BASHIR, A.. Brassinosteroids: a class of plant hormone. London:
Springer, 2011. p.193-242.

GONZÁLEZ-GARCÍA, M.-P.; VILARRASA-BLASI, J.; ZHIPONOVA, M.; DIVOL, F.; MORA-GARCÍA, S.; RUSSINOVA, E.; CAÑODELGADO, A. I.. Brassinosteroids control meristem size by promoting cell cycle progression in Arabidopsis roots. Development, Cambridge, v.138, n.5, p.849-859, 2011. DOI: http://doi.org/10.1242/dev.057331

GUMIERE, T.; ROUSSEAU, A. N.; COSTA, D. P.; CASSETARI, A.; COTTA, S. R.; ANDREOTE, F. D.; GUMIERE, S. J.; PAVINATO, P. S.. Phosphorus source driving the soil microbial interactions and improving sugarcane development. Scientific Reports, v.9, n.1, p.4400, 2019. DOI: http://doi.org/10.1038/s41598019-40910-1

GUPTA, A.; SINGH, M.; LAXMI, A.. Interaction between glucose and brassinosteroid during the regulation of lateral root development in Arabidopsis. Plant Physiology, Bethesda, v.168, n.1, p.307-320, 2015. DOI: http://doi.org/10.1104/pp.114.256313

HACHAM, Y.; HOLLAND, N.; BUTTERFIELD, C.; UBEDATOMAS, S.; BENNETT, M. J.; CHORY, J.; SAVALDI-GOLDSTEIN S.. Brassinosteroid perception in the epidermis controls root meristem size. Development, Cambridge, v.138, n.5, p.839848, 2011. DOI: http://doi.org/10.1242/dev.061804

HALING, R. E.; YANG, Z.; SHADWELL, N.; CULVENOR, R. A.; STEFANSKI, A.; RYAN, M. H.; SANDRAL, G. A.; KIDD, D. R.; LAMBERS, H.; SIMPSON, R. J.. Root morphological traits that determine phosphorus-acquisition efficiency and critical external phosphorus requirement in pasture species. Functional Plant Biology, v.43, n.9, p.815-826, 2016. DOI: http://doi.org/10.1071/FP16037

JIANG, Y.-P.; CHENG, F.; ZHOU, Y.-H.; XIA, X.-J.; SHI, K.; YU, J.$Q$.. Interactive effects of $\mathrm{CO} 2$ enrichment and brassinosteroid on $\mathrm{CO} 2$ assimilation and photosynthetic electron transport in Cucumis sativus. Environmental and Experimental Botany, Elmsford, v.75, p.98-106, 2012. DOI: http://doi.org/10.1016/i.envexpbot.2011.09.002

JOHNSON, N. C.; WILSON, G. W. T.; BOWKER, M. A.; WILSON, J. A.; MILLER, R. M.. Resource limitation is a driver of local adaptation in mycorrhizal symbioses. Proceedings of the National Academy of Sciences, Washington, v.107, n.5, p.2093-2098, 2010. DOI: http://doi.org/10.1073/pnas.0906710107

KARTAL, G.; TEMEL, A.; ARICAN, E.; GOZUKIRMIZI, N.. Effects of brassinosteroids on barley root growth, antioxidant system and cell division. Plant Growth Regulation, v.58, n.3, p.261-267, 2009 DOI: http://doi.org/10.1007/s10725-009$\underline{9374-z}$

KHAN, M. S.; ZAIDI, A.; AHMAD, E.. Mechanism of phosphate solubilization and physiological functions of phosphatesolubilizing microorganisms. In: KHAN, M. S.; ZAIDI, A.; MUSARRAT, J.. Phosphate solubilizing microorganisms. London: Springer, 2014. p. 31-62. DOI: http://doi.org/10.1007/978-3-319-08216-5 2

LANNES, L. S.; BUSTAMANTE, M. M. C.; EDWARDS, P. J.; VENTERINK, H. O.. Native and alien herbaceous plants in the Brazilian Cerrado are (co-) limited by different nutrients. Plant and Soil, The Hague, v.400, n.1-2, p.231-243, 2016. 
DOI: http://doi.org/10.1007/s11104-015-2725-9

LARRÉ, C. F.; MARINI, P.; MORAES, C. L.; AMARANTE, L.; MORAES, D. M.. Influence of the24-epibrassinolide on tolerance to salt stress in rice seedlings. Semina: Ciências Agrárias, Londrina, v.35, n.1, p.67-76, 2014. DOI: http://doi.org/10.5433/1679-0359.2014v35n1p67

LEE, H.-S.; KIM, Y.; PHAM, G.; KIM, J. W.; SONG, J.-H.; LEE, Y.; HWANG, Y.-S.; ROUX, S. J.; KIM, S.-H.. Brassinazole resistant 1 (BZR1)-dependent brassinosteroid signalling pathway leads to ectopic activation of quiescent cell division and suppresses columella stem cell differentiation. Journal of Experimental Botany, Oxford, v.66, n.15, p.4835-4849, 2015. DOI: http://doi.org/10.1093/jxb/erv316

LI, X.-J.; GUO, X.; ZHOU, Y.-H.; SHI, K.; ZHOU, J.; YU, J.-Q.; XIA, X.-J.. Overexpression of a brassinosteroid biosynthetic gene Dwarf enhances photosynthetic capacity through activation of Calvin cycle enzymes in tomato. BMC Plant Biology, v.16, n.1, p.1-12, 2016. DOI: http://doi.org/10.1186/s12870-016$\underline{0715-6}$

LISBOA, L. A. M.; HEINRICHS, R.; FIGUEIREDO, P. A. M.. Efeitos da fosfatagem nos atributos químicos do solo e produção de cana-de-açúcar para forragem. Boletim de Indústria Animal, Nova Odessa, v.74, n.3, p.213-220, 2017 DOI: http://doi.org/10.17523/bia.v74n3p213

LV, B.; TIAN, H.; ZHANG, F.; LIU, J.; LU, S.; BAI, M.; LI, C.; DING, Z.. Brassinosteroids regulate root growth by controlling reactive oxygen species homeostasis and dual effect on ethylene synthesis in Arabidopsis. PLoS Genetics, Washington, v.14, n.1, p.e1007144, 2018. DOI: http://doi.org/10.1371/journal.pgen.1007144

MCGUINESS, P. N.; REID, J. B.; FOO, E.. The role of gibberellins and brassinosteroids in nodulation and arbuscular mycorrhizal associations. Frontiers in Plant Science, Parkville, v.10, 2019. DOI: http://doi.org/10.3389/fpls.2019.00269

NOBERTO, P.; ALVARENGA, A. A.; ANDRADE, J. C.; RODRIGUES, F. A.; PEREIRA, L. V.; GONÇALVES, E. D.. Cultivo da figueira "purple valinhos" em diferentes densidades vegetais para produção de figos verdes para indústria na região do Campo das Vertentes-MG. Agricultural Sciences, v.9, p.1097-1106, 2018.

NOURI, E.; BREUILLIN-SESSOMS, F.; FELLER, U.; REINHARDT, D.. Phosphorus and nitrogen regulate arbuscular mycorrhizal symbiosis in Petunia hybrida. PLoS One, v.9, n.3, p.e90841, 2014. DOI http://doi.org/10.1371/journal.pone.0090841

OBERSTEINER, M.; PEÑUELAS, J.; CIAIS, P.; VAN DER VELDE, M.; JANSSENS, I. A.. The phosphorus trilemma. Nature Geoscience, v.6, n.11, p.897, 2013. DOI: http://doi.org/10.1038/ngeo1990

PINHEIRO, C.; CHAVES, M. M... Photosynthesis and drought: can we make metabolic connections from available data? Journal of Experimental Botany, Oxford, v.62, n.3, p.869882, 2011. DOI: http://doi.org/10.1093/jxb/erq340

RAIJ, B. V.; ANDRADE, J. C.; CANTARELLA, H.; QUAGGIO, J. A. Análise química para avaliação da fertilidade de solos tropicais. Campinas: IAC, 2001.
RAIJ, B. V.; CANTARELLA, H.; QUAGGIO, J. A.; FURLANI, A. M. C.. Recomendações de adubação e calagem para o Estado de São Paulo. Campinas: IAC, 1997.

RISKIN, S. H.; PORDER, S.; NEILL, C.; FIGUEIRA, A. M. S.; TUBBESING, C.; MAHOWALD, N.. The fate of phosphorus fertilizer in Amazon soya bean fields. Philosophical Transactions of the Royal Society B: Biological Sciences, v.368, n.1619, p.20120154, 2013. DOI: http://doi.org/10.1098/rstb.2012.0154

RODRIGUES, H. J. B.; COSTA, R. F.; RIBEIRO, J. B. M.; SOUZA FILHO, D. C.; RUIVO, M. L. P.; SILVA JÚNIOR, J. A. Variabilidade sazonal da condutância estomática em um ecossistema de manguezal amazônico e suas relações com variáveis meteorológicas. Revista Brasileira de Meteorologia, v.26, n.2, p.189-196, 2011. DOI: http://doi.org/10.1590/S0102-77862011000200003

RODRIGUES, M.; PAVINATO, P. S.; WITHERS, P. J. A.; TELES, A. P. B.; HERRERA, W. F. B.. Legacy phosphorus and no tillage agriculture in tropical oxisols of the Brazilian savanna. Science of the Total Environment, Amsterdam, v.542, p.1050-1061, 2016. DOI: http://doi.org/10.1016/j.scitotenv.2015.08.118

ROY, E. D.; RICHARDS, P. D.; MARTINELLI, L. A.; COLETTA, L. D.; LINS, S. R. M.; VAZQUEZ, F. F.; WILLIG, E.; SPERA, S. A.; VAN-WEY, L. K.; PORDER, S.. The phosphorus cost of agricultural intensification in the tropics. Nature Plants, v.2, p.16043, 2016. DOI: http://doi.org/10.1038/nplants.2016.43

SANTOS, H. G.; JACOMINE, P. K. T.; DOS ANJOS, L. H. C.; OLIVEIRA, V. A.; LUMBRERAS, J. F.; COELHO, M. R.; ALMEIDA, J. A.; ARAUJO FILHO, J. C.; OLIVEIRA, J. B.; CUNHA, T. J. F.. Sistema brasileiro de classificação de solos. Brasília: Embrapa, 2018.

SILVA, L.; MARCHIORI, P. E. R.; MACIEL, C. P.; MACHADO, E. C.; RIBEIRO, R. V.. Photosynthesis, water relations and growth of young coffee plants according to phosphorus availability. Pesquisa Agropecuária Brasileira, Brasília, v.45, n.9, p.965-972, 2010. DOI: http://doi.org/10.1590/S0100204X2010000900005

SILVA, M. C.; COSTA, F. R.; LEANDRO, W. M.; LIMA JUNIOR, A. F.; BRITO, G. S.; SILVA, L. R.. Eficiência de uso de termofosfato de alumínio como fonte de fósforo na produção de feijão, em solo incubado. Revista Eletrônica Faculdade Montes Belos, São Luís de Montes Belos, v.9, n.1, p.1-18, 2015.

SIMÕES NETO, D. E. S.; OLIVEIRA, A. C.; FREIRE, F. J.; FREIRE, M. B. G. S.; OLIVEIRA, E. C. A.; ROCHA, A. T.. Adubação fosfatada para cana-de-açúcar em solos representativos para o cultivo da espécie no Nordeste brasileiro. Pesquisa Agropecuária Brasileira, Brasília, v.50, n.1, p.73-81, 2015. DOI: $\underline{\text { http://doi.org/10.1590/S0100-204X2015000100008 }}$

SINGH, A. P.; SAVALDI-GOLDSTEIN, S.. Growth control: brassinosteroid activity gets context. Journal of Experimental Botany, Oxford, v.66, n.4, p.1123-1132, 2015. DOI: http://doi.org/10.1093/ixb/erv026

SOKA, G.; RITCHIE, M.. Arbuscular mycorrhizal symbiosis and 
ecosystem processes: Prospects for future research in tropical soils. Open Journal of Ecology, v.4, n.1, p.11, 2014. DOI: http://doi.org/10.4236/oje.2014.41002

SOLTANGHEISI, A.; SANTOS, V. R.; FRANCO, H. C. J.; KOLLN, O.; VITTI, A. C.; DIAS, C. T. S.; HERRERA, W. F. B.; RODRIGUES, M.; SOARES, T. M.; WITHERS, P. J. A.. Phosphate Sources and Filter Cake Amendment Affecting Sugarcane Yield and Soil Phosphorus Fractions. Revista Brasileira de Ciência do Solo, Viçosa, v.43, 2019. DOI:

http://dx.doi.org/10.1590/18069657rbcs20180227

\section{TAIZ, L.; ZEIGER, E.; M ØLLER, I. M.; MURPHY, A.. Fisiologia e} desenvolvimento vegetal. Porto Alegre: Artmed, 2017.

VENTERINK, H. O.. Legumes have a higher root phosphatase activity than other forbs, particularly under low inorganic $P$ and N supply. Plant and Soil, v.347, n.1-2, p.137-146, 2011. DOI: http://doi.org/10.1007/s11104-011-0834-7

VENTERINK, H. O.; GÜSEWELL, S.. Competitive interactions between two meadow grasses under nitrogen and phosphorus limitation. Functional Ecology, Oxford, v.24, n.4, p.877-886, 2010. DOI: http://doi.org/10.1111/j.1365$\underline{2435.2010 .01692 . x}$

VIERHEILIG, H.; COUGHLAN, A. P.; WYSS, U. R. S.; PICHÉ, Y.. Ink and vinegar, a simple staining technique for arbuscularmycorrhizal fungi. Appl. Environ. Microbiol., v.64, n.12, p.5004-5007, 1998. DOI: http://doi.org/10.1128/AEM.64.12.5004-5007.1998
WACLAWOVSKY, A. J.; SATO, P. M.; LEMBKE, C. G.; MOORE, P. H.; SOUZA, G. M.. Sugarcane for bioenergy production: an assessment of yield and regulation of sucrose content. Plant Biotechnology Journal, Oxford, v.8, n.3, p.263-276, 2010. DOI: http://doi.org/10.1111/j.1467-7652.2009.00491.x

WANG, X.; SHEN, J.; LIAO, H.. Acquisition or utilization, which is more critical for enhancing phosphorus efficiency in modern crops?. Plant Science, Limerick, v.179, n.4, p.302306, 2010. DOI: http://doi.org/10.1016/i.plantsci.2010.06.007

WEI, Z.; LI, J.. Brassinosteroids regulate root growth, development, and symbiosis. Molecular Plant, Oxford, v.9, n.1, p.86-100, 2016. DOI: http://doi.org/10.1016/j.molp.2015.12.003

YANG, H.; ZHANG, Q.; DAI, Y.; LIU, Q.; TANG, J.; BIAN, X.; CHEN, X.. Effects of arbuscular mycorrhizal fungi on plant growth depend on root system: a meta-analysis. Plant and Soil, The Hague, v.389, n.1-2, p.361-374, 2015. DOI: http://doi.org/10.1007/s11104-014-2370-8

ZHANG, Y. P.; ZHU, X. H.; DING, H. D.; YANG, S. J.; CHEN, Y. Y.. Foliar application of 24-epibrassinolide alleviates hightemperature-induced inhibition of photosynthesis in seedlings of two melon cultivars. Photosynthetica, Prague, v.51, n.3, p.341-349, 2013. DOI: http://doi.org/10.1007/s11099-013-0031-4

A CBPC - Companhia Brasileira de Produção Científica (CNPJ: 11.221.422/0001-03) detém os direitos materiais desta publicação. Os direitos referem-se à publicação do trabalho em qualquer parte do mundo, incluindo os direitos às renovações, expansões e disseminações da contribuição, bem como outros direitos subsidiários. Todos os trabalhos publicados eletronicamente poderão posteriormente ser publicados em coletâneas impressas sob coordenação da Sustenere Publishing, da Companhia Brasileira de Produção Científica e seus parceiros autorizados. Os (as) autores (as) preservam os direitos autorais, mas não têm permissão para a publicação da contribuição em outro meio, impresso ou digital, em português ou em tradução. 